\title{
TIME OUT FOR FAMILY: SHIFT WORK, FATHERS, AND SPORTS
}

\author{
LAWRENCE S. ROOT AND LYNN PERRY WOOTEN
}

Shift work is a fact of life for many workers. Almost one in six full-time hourly and salary employees works a shift outside the 6 a.m. to 6 p.m. window that researchers use to define the temporal bounds of the traditional workday. Almost half of those working in restaurants and bars work such alternate shifts, as do more than a quarter of workers in hospitals and manufacturing facilities. Drawing on interviews and observations in a Midwestern auto parts plant, this study explores how individuals in this predominantly male workforce talk about fulfilling family responsibilities in the face of relatively inflexible shift schedules. Interviews and observations reveal how the time pressures of shift work, particularly the afternoon-evening shift, affect the ability of fathers to participate in their children's activities, especially organized sports. Without formal options for scheduling flexibility, workers turn to a variety of informal approaches, such as ad hoc arrangements with sympathetic supervisors or the assistance of coworkers in covering for absences. In extreme cases, workers may engage in independent actions, often placing their jobs at risk. These findings contribute to the literature on work-family conflict and the gender dynamics of work-family life programs. By emphasizing the importance of including fathers in the work-family equation, they have practical implications for both employers and policymakers concerned with addressing the challenges of helping a contemporary workforce strike an equitable balance between work and family life. (C) 2008 Wiley Periodicals, Inc.

Keywords: work family conflict, culture and climate, emotion, quality of work life, qualitative research, social networks, corporate culture

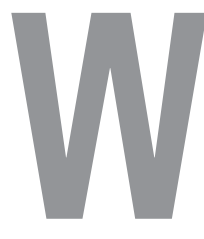

hen James Anderson ${ }^{1}$ talks about his relationship with his children, sports are a central theme:

I always kept a job where I could stay days because I had two boys and two girls and they all were on one of my teams or another. So I always had basketball, football, softball, Branford Raiders, flag football, or whatever. All year round. Whatever it was, my kids were always on the team. So when I came home, they came home with me.

Unlike many at the plant, Anderson was able to work the day shift, freeing up his late afternoons and evenings. But occasionally there were glitches. Once, during a period 
when he was regularly working Saturdays, the football team he coached had a championship game:

I told that foreman on Monday of that week that we got the championship game, which is like a Super Bowl, our league against the other league-the top team. We got this Super Bowl game Saturday. I got to leave no later than 12 or I'm not goin' come that Saturday at all. He said, "Well, come on in, and I'll make sure you get off."

I get there that Saturday mornin', I'll never forget that. I said, "Phil, you know I gotta leave at 12."

“... I can't let you go."

I said, "Phil, I told you about it."

"Yeah, but I gotta run this job, I can'tno, no."

When his supervisor

wouldn't allow him

the flexibility he

needed, Anderson

took matters into his

own hands.
All right. So I go to lunch at 11. I go to the pay phone, stick my little money in, call back in, and say, "Hey, my car fell in a ditch. I'm waitin' for AAA to come. I don't know how long they gonna be." Okay. I said, "I may be back and I may not." So to the game I go.

Come back in that Monday and, at that time, I was workin' off the line doin' shock repair. I was just repairin' shocks on the side. Just take 'em off the line and, don't nothin' come of it, set 'em down. I come back that Monday, he posted my job on the board. Now here's a man put in for it with 20 more years' seniority than me. Now I'm back on the line workin'.

When his supervisor wouldn't allow him the flexibility he needed, Anderson took matters into his own hands. As a result, he lost his less-pressure, "off-line" repair job and had to go back to the assembly line. But to him, fulfilling his commitment to coaching the team was worth the sacrifice.

\section{The Conflict Between Family and Work Life}

Working families often grapple with tensions that result when work and family demands conflict (Frone \& Yardley, 1996; Hochschild, 1997; Parasuraman \& Greenhaus, 1997; Presser, 2003; Schor, 1991). Some analysts propose that such problems arise from "spillover" effects that occur when the negative aspects of work affect a worker's family relationship (Barnett \& Marshall, 1992; Secret \& Sprang, 2001). Others point to the related concept of inter-role conflict, in which "the role pressures from the work and family domains are mutually incompatible in some respect" (Greenhaus \& Beutell, 1985, p. 7). The broad issue of work-family conflict has been divided into that caused by the impact of work on family and that caused by the impact of family on work (Frone, Russell, \& Cooper, 1992; Netemeyer, Boles, \& McMurrian, 1996). As James Anderson's experience shows, the impacts can be reciprocal. His work responsibilities threatened to undercut a key nonwork commitment and, in his response, his family commitments ended up interfering with work. The reciprocal nature of work-family conflict also has been noted by researchers who have tried to understand the tensions between the spheres of work and home (Dallimore \& Mickel, 2006). A starting point for understanding these organizational dynamics is "the premise that organizations are conflicted sites of human activity" (Tretheway \& Ashcraft, 2004, p. 82) that can create a variety of tensions between the individual and the organization.

Research and the popular press frequently portray work-family conflict as a "mother's issue" and neglect the experiences of fathers (Kerry \& Palkovitz, 2004). In a comprehensive review of work-family research in management journals, Eby and her colleagues found a strong focus on women and work-family, with only a small portion of the research devoted to men and work-family issues (Eby, Casper, Lockwood, Bordeaux, \& Brinley, 2005). But so- 
cietal pressures, changing values, and demographic trends in the workplace are leading fathers to take a more active role in parenting. That role has expanded beyond the traditional one of breadwinner and disciplinarian to include more child-rearing activities (Almeida \& McDonald, 2005; Bonney, Kelley, \& Levant, 1999; Hill, 2005). Although mothers still spend more time with their children than fathers do, the difference between the respective time commitments in a two-parent family has decreased. Today, fathers spend about $65 \%$ as much time with their children as mothers do on weekdays and about $87 \%$ as much time on weekends, compared to the 1970s and 1980s when fathers spent $30 \%$ to $45 \%$ as much time with their children as mothers did (Pleck, 1997; Yeung, Sandberg, Davis-Kean, \& Hofferth, 2001). Fathers are providing more emotional support to their children, engaging in hands-on interactions, and participating in such daily care responsibilities as diaperchanging and grooming. A large proportion of their time with their children is spent in conventional leisure activities, such as scouting and sports (Yeung et al., 2001).

With fathers spending more time on parenting, they increasingly face work-family conflicts. Their participation in parenting activities may be seriously challenged by rigid work schedules, particularly nontraditional ones (Presser, 2003). About one in six workers in the United States works an alternative work schedule, defined as one that either starts before 6 a.m. or ends after 6 p.m. (Beers, 2000). Almost half of those working in restaurants and bars work an alternative shift, as do a quarter of hospital workers and those in manufacturing. Faced with demanding-and, in some instances, nonconventional-work schedules and expanding parenting responsibilities, fathers are increasingly grappling with the challenges of managing work-family conflict (Levine \& Pittinsky, 1997; Reeves, 2002). With fathers more involved in their children's lives and with some coping with the issues associated with nontraditional work schedules, what affect does this have on work-family dynamics, and how should workplace policies and practices respond?
Those questions arose during a series of ethnographic interviews undertaken to study what auto workers thought about career options for their children in the face of shrinking opportunities in manufacturing, an employment path that once provided well-paying jobs without requiring higher education. Workers often talked about the problems of meeting family responsibilities in a production environment characterized by shift work and inflexibility. They frequently brought up the challenges of the afternoon shift, because it precluded having either afterschool or evening time with family. The researchers noted that a number of the workers independently raised the issue of not being able to be a part of their children's organized sports. As Ralph, a worker in his 50s, recalled, his son now coaches a swimming team, but "I never got to see him do any of his extracurricular activities because most of my time I spent on the number 3 [afternoon] shift."

Other instances when work schedules interfered with family responsibilities included caring for a sick child, meeting with teachers, or attending children's concerts or other performances. But the desire to participate in or watch organized sports stands out in several ways. First, it was clear that being able to share their children's sports experience was particularly important to the men who brought it up in interviews. Older workers spoke with sadness about missing out on this aspect in the lives of their now grown children; younger workers expressed their determination not to have this happen to them. Second, the structure of organized sports, with games scheduled in the afternoon or evening, directly conflicts with the afternoon shift at plants. Unlike a child's sudden illness or the occasional time conflict raised by a music performance or appointment with a teacher, organized sports schedules systematically preclude afternoon-shift workers from participating in an ongoing aspect of their children's lives. It is simply a 
case of one rigid schedule confronting another. Third, several workers talked about how they took independent action when faced with a work-family sports event conflict. For these reasons, the situation of organized sports seemed to epitomize a core problem of work-family time conflicts and the tensions inherent in trying to deal with the conflicting demands of work and home.

To find out how fathers navigate a relatively inflexible work environment to maintain involvement in their children's sport activities, we conducted further research among the predominantly male workforce in an automotive manufacturing plant. The research team used a variety of ethno-

Shift work, the

rigidity of

production

schedules

conflicting with

fathering

responsibilities, and

strategies to cope

with work-family

conflict were

common themes

that emerged. graphic techniques, such as observing participants, job shadowing, attending workplace and union functions, and working on the assembly line. The researchers also negotiated with factory management to conduct interviews at the factory with a randomly selected sample of hourly and salaried employees. In addition, several key managers and union leaders also were interviewed. About one-third of the 59 individuals interviewed were in management positions, while the balance were hourly workers, both line production workers and skilled trades. They ranged in age from early 20s to over 60. About $70 \%$ were male. There was some oversampling of women because they are underrepresented in the workforce.

The interviews were based on an openended, semistructured protocol covering the respondents' background and work experience, their views of auto work for themselves and their children, problems coordinating work and family, and their involvement in organizations outside the workplace. It also probed their views of what it meant to do a good job and to live a good life.

The interviews were tape-recorded and transcribed. Field notes and interview data were coded and analyzed using the Atlas.ti software package to identify common themes (Miles \& Huberman, 1994; Strauss \& Corbin, 1998). During the coding process, themes were organized into a set of categories, using the textual approach described by Gephart (1993). The authors focused on interview responses that discussed how the time commitments at work affected a father's ability to participate in family activities. Such reflective narratives capture the personal meaning of daily situations by depicting characters, settings, problems, actions, and resolutions (Ollerenshaw \& Creswell, 2002; Van Manen, 1990). Thus, they enable researchers to understand how employees resolve complex problems (Bell \& Nkomo, 1992; Muller \& Rowell, 1997).

Key codes included shifts, sports, work/nonwork, and ambience-environment. Once these elements were identified, key passages were recontextualized and interpreted for theoretical meaning. The coding process was iterative and allowed the researchers to fit accounts into categories and refine categories as new themes emerged. For instance, after retrieving relevant interviews, the authors coded passages relating to how fathers balance parenting responsibilities with shift work. Shift work, the rigidity of production schedules conflicting with fathering responsibilities, and strategies to cope with work-family conflict were common themes that emerged. Other data, such as field notes, articles about the plant, and union communications, also were incorporated into the Atlas.ti dataset. The discussion of the nature of the workplace and current operations drew upon this range of information. The specific individuals quoted about coping are described in Table I.

Through this qualitative lens, we see how fathers seek to be involved in the lives of their children in the face of the demands of shift work. Our analysis focuses on how fathers develop informal strategies, including actions that can be detrimental to the working environment, to allow participation in the sports activities of their children in the face of a dearth of formal options for accommodating pressing family demands. We conclude the article by discussing the implica- 


\section{T A B L E I Profiles and Coping Strategies of Workers}

\begin{tabular}{|c|c|c|c|c|c|}
\hline Pseudonym & Job & Race & $\begin{array}{l}\text { Age } \\
\text { Range }\end{array}$ & $\begin{array}{l}\text { Number of } \\
\text { Children }\end{array}$ & Coping Strategy \\
\hline Bill & $\begin{array}{l}\text { Hourly, Skilled } \\
\text { Trades }\end{array}$ & White & $20-29$ & 2 & $\begin{array}{l}\text { Coworkers in the plant would cover for this } \\
\text { father when he attended sports events; part } \\
\text { of the "family aspect" in the plant. }\end{array}$ \\
\hline Cecil & $\begin{array}{l}\text { Hourly, Skilled } \\
\text { Trades }\end{array}$ & White & $40-49$ & 4 & $\begin{array}{l}\text { Relied on cooperative supervisors to be } \\
\text { able to get time off to watch his daughter } \\
\text { cheerlead at sports events. }\end{array}$ \\
\hline James & $\begin{array}{l}\text { Hourly, } \\
\text { Production }\end{array}$ & $\begin{array}{l}\text { African } \\
\text { American }\end{array}$ & $50-59$ & 4 & $\begin{array}{l}\text { Usually was able to stay on the day } \\
\text { shift; when overtime was suddenly required } \\
\text { after he had been promised that he would } \\
\text { be off to coach the championship game, he } \\
\text { pretended he had a car accident at } \\
\text { lunchtime and didn't return to work. }\end{array}$ \\
\hline Gary & $\begin{array}{l}\text { Salaried } \\
\text { (formerly } \\
\text { hourly) }\end{array}$ & White & $50-59$ & 3 & $\begin{array}{l}\text { Talked about the supportive nature of his } \\
\text { supervisor, who had a "family orientation" } \\
\text { and helped him when he needed time off } \\
\text { for his family. }\end{array}$ \\
\hline Greg & $\begin{array}{l}\text { Hourly, } \\
\text { Skilled Trades }\end{array}$ & White & $50-59$ & 4 & $\begin{array}{l}\text { When on the afternoon shift, he coached } \\
\text { during his "lunch" break, which he infor- } \\
\text { mally extended, often with tacit supervisory } \\
\text { agreement. He also sometimes had pay } \\
\text { docked when a supervisor caught him tak- } \\
\text { ing too much time for his break. }\end{array}$ \\
\hline Melvin & $\begin{array}{l}\text { Hourly, } \\
\text { Production }\end{array}$ & White & $50-59$ & 4 & $\begin{array}{l}\text { Described how he could sabotage the work } \\
\text { process if a supervisor didn't allow him } \\
\text { time off. }\end{array}$ \\
\hline Ralph & $\begin{array}{l}\text { Hourly, } \\
\text { Production }\end{array}$ & $\begin{array}{l}\text { African } \\
\text { American }\end{array}$ & $50-59$ & 7 & $\begin{array}{l}\text { Described how being on the afternoon } \\
\text { shift kept him from seeing his son, now a } \\
\text { swim coach, swam competitively when he } \\
\text { was in school. }\end{array}$ \\
\hline
\end{tabular}

tions of our findings for human resource management research and practice.

\section{Sylvania as a Research Site}

"Sylvania" is a pseudonym for an auto components plant in the Midwest. At the beginning of our research in 2001, the workforce included more than 1,000 hourly workers, members of the United Auto Workers (UAW), the principal union for auto workers, and about 120 salaried employees, including first-line production supervisors, managers, engineers, sales personnel, and clerical work- ers. Since then, the size of the workforce has steadily shrunk. In 2006, the number of hourly UAW workers had dropped to 650, and salaried employment had seen a similar decrease. The plant is now scheduled to close completely, although this was not known during the period of data collection.

In this article, we are drawing upon data collected as part of the larger ethnographic study at Sylvania. This involved research activities such as participant observation at the plant, in meetings, at the local union, and at other work-related events. In addition, 59 workers and managers participated in indi- 
vidual open-ended interviews, lasting between one and two hours each. Most of the quotes used in this article, including the opening quote from James, came from the transcriptions of these interviews.

About 75 percent of the Sylvania workforce was male. Whites made up almost three-quarters of the hourly workers; African Americans accounted for most of the other employees. During the 1980s and early 1990s, there was virtually no hiring at Sylvania. As a result, most workers were either in their 20s and 30s (hired since the mid-1990s) or in their late 40s or older. Slightly more than a third of the hourly workers were eligible for retirement; they were either 55 or older with ten years in the plant, or younger than 55 with at least 30 years of service.

The auto components market in which Sylvania operates is highly competitive and has experienced massive changes in recent years. This is the result of increased global competition, as well as changes in the structure of the industry (Ingrassia \& White, 1994; Maynard, 2003; Womack, Jones, \& Roos,
1990). Many auto components plants, such as Sylvania, formerly were part of the Big Three auto makers (General Motors, Ford, and Chrysler) and their employees enjoyed the high pay and good benefits that were part of the contracts negotiated with the UAW. In a major reorganization, these component plants were split off and they now face an uncertain future (Root, 2006). The employment declines at Sylvania reflect a long-term drop in the Midwestern auto parts industry, which lost more than 50,000 jobs over the last 15 years, almost $13 \%$ of the area's total workforce (Collins, McDonald, \& Mousa, 2007).

The work process at Sylvania, like that in other manufacturing environments, has very limited opportunities for individual flexibility in work schedules. Based on our observations and interviews, we can rank the types of jobs in the plant according to the control the individual worker can exercise over time on the job (see Figure 1). At one extreme are the managers, salespeople, engineers, and other nonproduction personnel. They are generally scheduled for a standard eighthour workday, although, in practice, many

- Salaried: nonproduction

\section{More Control}

-managers, finance, sales, etc.

- Salaried: production/supervision

-front-line supervisors, area supervisors, etc.

- Hourly: skilled trades

-electricians, repair personnel, etc.

- Hourly: production ("off-line")

-cleaners, loading dock, etc.

- Hourly: production ("machine tender")

-modular/individual machine operations

- Hourly: production (assembly line)

-work stations linked to other work stations

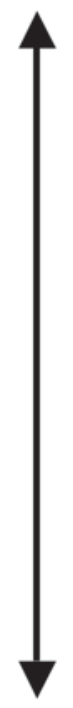

\section{Less Control}

FIGURE 1. Jobs at Sylvania and Individual Control OverTime 
salaried employees are expected to do casual-that is, unpaid-overtime. Although many work long hours, these employees are generally least tied to a rigid schedule. Their flexibility may be limited by group work on projects and deadlines, but they have the greatest opportunity for adjusting their schedules to meet individual needs.

Of those directly involved in production, assembly-line workers, who are tied to a continuous and interlocking process, have the least opportunity for individual flexibility. They usually have to find a relief person, even if they have to leave their work station for a short time. Machine tenders oversee the operations of a machine, feeding raw materials in, stacking the product of the machine, and making adjustments when needed. They tend to have some flexibility because they can adjust their speed to "work ahead" and then take breaks. In some cases, there may be little to do during relatively long periods of time. Those in "off-line jobs," such as the skilled trades, cleaners, and inspectors, tend to move around the plant on their own, doing repairs, maintenance work, and machine set-ups. Working independently at their own pace, they tend to be less closely supervised. Salaried production supervisors, the front-line managers responsible for particular production sites, also may have some flexibility. Although they tend to be tied to their production areas, they often can arrange for alternate supervision when they need to be away from their work areas.

Thus, among the hourly workforce, opportunities for individual flexibility are determined by one's job, which, in turn, is mainly based on seniority in the plant. In a unionized facility such as this, the rules for job assignments are negotiated between management and the union. Although assignments take into account the employee's ability to do a job, most jobs are generic enough that seniority becomes the determining factor. A worker on the afternoon shift can request ("bid on") a day-shift job. But because the outcome will primarily be determined by seniority, younger workers-those most likely to have school-age children-are less likely to get the shift of their choice. Although the union has been an important and successful advocate for work-family programs, such as day care and increased support services, on the local level, the negotiated rules governing job and shift assignments tend to work against the consideration of family issues in scheduling work.

\section{Work-Family Conflict and Shift Work}

Research suggests that shift work affects the psychological and emotional wellbeing of employees, with serious consequences for family life (Costa, 1996; Staines \& Pleck, 1984), and that greater flexibility reduces some of these conflicts (Staines \& Pleck, 1986). The workfamily conflicts associated with afternoon or evening shifts arise because workers have to neglect the key family responsibilities that typically occur after school and in the early evening. (Demerouti, Geurst, Bakker, \& Euwema, 2004). Shift workers often are unavailable for the range of parenting activities that typically occur during the evening and afternoon, such as personal care activities (grooming, medical appointments, meal preparation), play and companionship activities, achievement-related activities (homework, reading, educational lessons), and extracurricular activities (sports, scouting, religious classes, music lessons) (Yeung et al., 2001). Employees describe auto plants as notoriously indifferent to the impact of scheduling on workers and their families. For example, a salaried production supervisor described the effect of shift work scheduling on workers and their families:

I mean, it's a known thing if you work in the auto industry, they own you, especially in a plant environment, maybe not staff, maybe not downtown, but especially in a plant environment. They
Shift workers often

are unavailable for

the range of

parenting activities

that typically occur

during the evening

and afternoon, such

as personal care

activities (grooming, medical

appointments, meal

preparation), play

and companionship

activities,

achievement-related activities

(homework, reading, educational lessons). 
own you, meaning you work and you work your ass off and you work a lot of hours.

I know some of the guys here. You can work third shift for two weeks, then all of a sudden you're on first shift. And in production, there's no stability on what you're doing and whatever hours the line is running, you have to be out there to supervise them, which makes it hard. Some of the guys out there who have been doing this for years, I don't know [pause] how their kids know who they are. I have no idea. And that's sad, to me. Another guy that does work here, his father worked, you know, when he was growing up his father worked in the automotive industry and he's like, "I never knew my dad."

Sylvania's production environment posed particular chal-

"Some of the guys lenges for reconciling the competing demands of work and family. There were two main shifts: days (roughly 8 a.m. to 4 p.m.) and afternoons (4 p.m. to midnight). There was also a midnight shift, primarily for maintenance and repair rather than production. Some workers preferred the afternoon (second) shift, from 4 p.m. to midnight, but it was uniformly considered the worst shift for those with family responsibilities. A skilled tradesman in his early 50s described how he enjoyed the timing and the more relaxed atmosphere on the afternoon shift when he was younger:

There's less pressure in the plants, less supervision around, a more relaxed atmosphere to work. You get off at 11 or 12 at night. If you want to go out, you can go out ... I'm not a morning person, so sleeping in until I felt like getting up was great. You know, I'd get up in the morning at 9 or 10 and go to the beach, lay around the lake for a couple hours before I came to work. . . . Work- ing in the afternoon is a more relaxed atmosphere to work . . . you don't have the engineers, you don't have as much supervision around, you're just working-it's like you get your job done, everything's good.

But once he had children, working in the afternoon became a major problem, particularly once his children reached school age:

... if your kids are in school, it's even worse. You don't see them except on the weekends. They're in school all day. You might see them in the morning. You get up in the morning and take them to school. But by the time they get out of school, you're at work and by the time you get home from work, they're in bed. So you see them in the morning to take them to school and that's it. See, there's no time. There's no family time, other than the weekend.

The late afternoon starting time for the second shift at Sylvania was particularly problematic. A production worker who had transferred into the plant recalled that the second shift at her old plant used to start at 7 p.m. When the second shift started in the early evening, she was able to have time with her children after school and at dinner:

... you could be home with your family for dinner and stuff . . . It helped. It really did. Because that way you could be there with your kids to do the homework thing. When ... they switched the hours [to a 4 p.m. start], then it was harder. I'd see my kids for 10 minutes and that was it. Bye.

Another production worker in his 50s talked of his assignment to the afternoon shift as if it were a life sentence:

I stayed on afternoons for 29 years. . . . No matter what classification I held or where my job was, I was always stuck on afternoons ... never seeing your family. 


\section{Fathering and Sports}

The frustration expressed by Sylvania workers about the afternoon shift often found its strongest expression when fathers discussed their efforts to be involved in a child's organized sports activities. The situation of organized sports brings together two elements for these working fathers. First, it reflects the important role that organized sports plays in the parenting relationships of many fathers. Second, the time conflicts between work and home are stark, as a rigid work schedule confronts the rigidity of children's athletic competition schedules.

The emphasis on sports that was observed in interviews is consistent with the way many observers discuss fathering. For example, the discourse of the Fatherhood Responsibility Movement couches domestic responsibilities in masculine terms by urging men to be involved with their children but differentiating this involvement from traditional mothering activities (Gavanas, 2004). This articulation of masculinity places a premium on paternal responsibility through involvement in certain fathering activities (Connell, 1995). A lack of paternal involvement in child rearing is often seen as arising from the physical separation of men's work from the home that came with industrialization and the emergence of a marketplace economy in the nineteenth century. The majority of parenting responsibilities became associated with maternal roles, whereas fathering responsibilities became defined as breadwinning in the workplace. As fathers withdrew from home life so they could ensure their families' financial well-being, parenting experts encouraged them to get more involved in their children's lives (Griswold, 1993). Fathers then began to create a "male" mode of domesticity, which accommodated traditional work schedules by involving dads in fun after-work activities that reinforce masculinity. Many of these activities, such as sports or scouting, engage fathers in prototypically male pursuits that value competition, physical strength, and aggression (Messner, 1992). James Anderson's interview provides an example when he talks about how playing football taught his boys to stand up for themselves when they were being bullied:

'Cause my boys back then when they was 11 or $12 \ldots$ they lived the good life. They lived in a brick home-three bedrooms, all this stuff-ranch. You go out here on the field and meet some people that don't eat like you do and don't live like you do. I'm gonna seecan you mix with them? And it was a while where [other kids] would pick at 'em and do little things and you know thump 'em upside the head 'cause they was the coach's kid. And I told 'em, "They hit you, you hit 'em back.... You put that shoulder pad and helmet on, you get out there and knock the hell outta somebody." And that's what they did. So, like I said, they successful now.

Greg, another Sylvania employee, described organized sports as the context in which he appeared to have based much of his relationship with his children:

In a way, like I say, I spent a lot of time with the kids, but it was on a football field or a baseball field or on a wrestling mat someplace, you know. And I can't really say when I look
The frustration expressed by

Sylvania workers

about the afternoon

shift often found its strongest

expression when

fathers discussed

their efforts to be

involved in a child's

organized sports

activities. back on it, ya know, you say, well, the kids have spent time with me, you know what I mean? I can't say I put work ahead of everything else, because I was still out there on the field for 'em. I went to all their games.

\section{Developing Coping Mechanisms to Gain Flexibility}

As shown in Figure 2, when the plant's formal structure did not allow fathers to participate in their children's organized sports or other activities, informal approaches come 


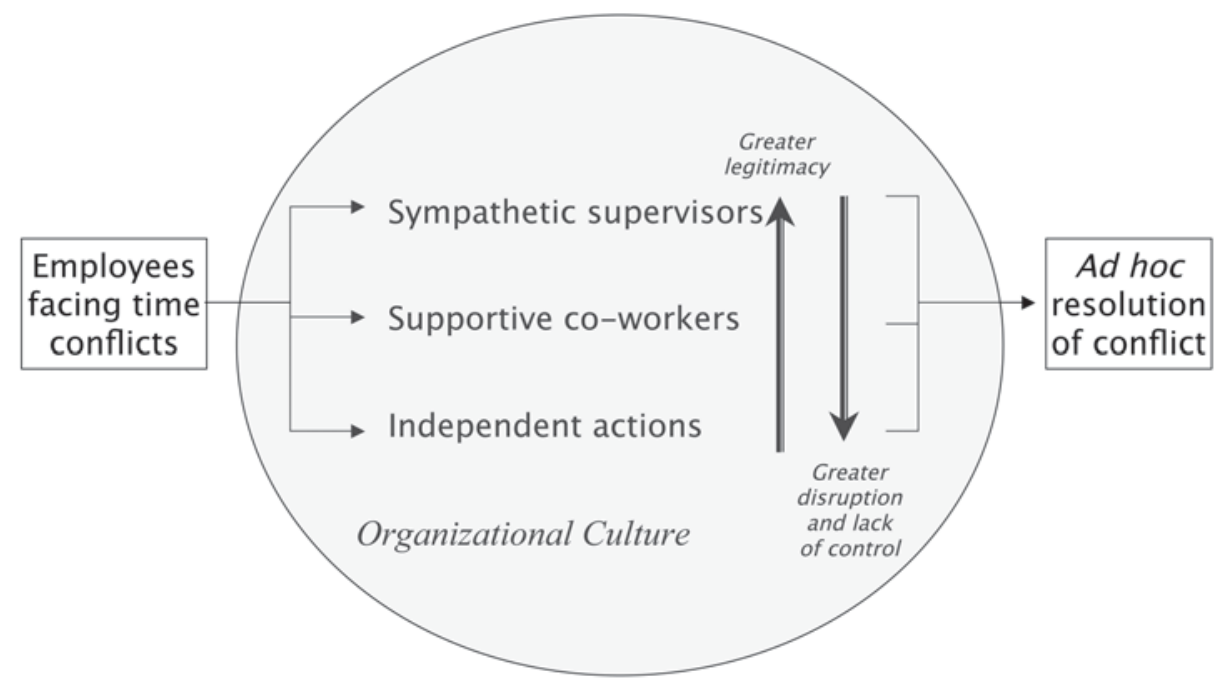

FIGURE 2. Work-Family Time Conflicts: Coping Strategies in the Absence of Formal Human Resource Support

into play. Three strategies emerged from the analysis of the interview data: getting permission from a sympathetic supervisor, using informal support (coverage) from coworkers, and taking independent action, such as James Anderson's decision to pretend he had an auto accident so that he could meet his obligations as a coach in the football championship game. These three approaches, which are all outside the formal structures of the workplace, range from least disruptive (arranging time off with a cooperative supervisor) to highly disruptive (independent actions that interfere with work that needs to be done).

\section{Getting Permission From a Sympathetic Supervisor}

Supervisors are often the gatekeepers for managing work-family conflict. They are the link to organizational resources and may have the power to modify work schedules to accommodate parenting obligations (Friedman \& Johnson, 1997; Scandura \& Lankau, 1997; Wooten \& Finley, 2003). As gatekeepers, supervisors play an important role in empowering employees to manage the domains and borders of work and family (Bowen, 1988; Clark, 2000). Furthermore, a supervisor helps buffer the stressors of work- family conflict by being sensitive to an employee's family responsibilities, providing emotional support, and accommodating an employee's need for flexibility (Warren \& Johnson, 1995). This results in employees who are appreciative of the supervisor's respect for their family obligations (Haddock, Zimmerman, Lyness, \& Ziemba, 2006).

At Sylvania, sympathetic supervisors played a significant role in helping fathers participate in their children's sports events, despite the rigidity of the plant's work schedule. For instance, Greg, a 50-year-old father of four boys, relates how he was able to coach baseball teams season after season, even though he was on afternoons:

... it's a pretty laid-back plant ... I was still able to coach three of 'em in baseball ... I got off, took a long lunch, lunch being around 6 o'clock-6 to about 8 ... No horseshoes, no beer, but coaching ... Go over there and coach baseball. And the boss caught me, he'd dock me or whatever, ya know. That was just understood, ya know.

For a while there I'd tell the boss, "Hey, I gotta leave." I says, "Ya know, I'll work an hour over or somethin'." "Okay, fine no problem." They were flexible, ya 
know. So I'd go over there, I'd coach the baseball team, come back to work.

. . . Started out little league, I started with 12-year-olds. I'd coach 12-yearolds in baseball. . . . I ended up in JV baseball in high school. Coached junior high wrestling. And coached varsity football and junior high football as a matter of fact. ... Did a lotta coaching.

Cecil, a skilled tradesman in his 40 s, relates a similar story of how, with his supervisor's support, he would leave the plant to attend his daughter's cheerleading events:

I'd give up Friday night, a couple hours, and tell my boss to stop my pay. I'd go to football games and watch her cheer, come back and go to work. As long as you're in an off-line job in the afternoon shift, the bosses are fairly flexible.

Cecil believed this kind of informal flexibility depended on whether the employee was considered a good worker and the personality of the supervisor:

And that's situations where you run into trouble and here you get new supervisors who are people who want to make a name for themselves. And they're not very good "people persons" like they should be. You can spot them. You can look at the numbers and spot them right off the bat where all the trouble is. Where's the absenteeism? Where's the 4600s [written disciplinary reports]? . . . They will follow that person around.

Gary, a salaried worker, spoke of how supervisors' family values also affected their flexibility to attend a child's sporting event or other family activities:

My boss was great ... [he] knew what my issues were with my wife ... his family values are strong like mine. The family comes first. He has never given me a hard time for taking time off for my family.
Such comments reinforce research findings that informal flexibility strongly depends on the supervisor's personal beliefs, orientation, and experiences with balancing work and family (Anderson, Coffey, \& Byerly, 2002; Powell \& Mainiero, 1999). Possibly these beliefs or experiences counteract the traditional detachment of management from family life and the rationale that it is management's responsibility to protect the organization from these outside influences (Bruce \& Reed, 1994). Hence, when supervisors' family values are aligned with those of their workers, workers find it easier to navigate both work and family domains, and there is less tension caused by conflicting demands (Clark, 2000).

Supervisors are often the

\section{Using Informal Support from Coworkers}

Coworkers also can help each other juggle work and family by serving as an extended, informal kinship network or a clan that provides psychological support and takes a collective approach to work (Haddock et al., 2006; Ouchi, 1980). Workers at Sylvania often used family terms to describe the culture in the plant, suggesting a working environment emphasizing group goals and cooperation. Moreover, they appeared to import family values from home that were not only displayed in the work culture, but were also manifested in camaraderie and social support. Social networks formed by peers in the workplace can provide emotional support and instrumental assistance in coping with stress in the workplace (Billings \& Moos, 1982; Haas \& Hwang, 1995).

Bill, a 26-year-old, described how his father, who worked at Sylvania for more than 30 years, "would always find a way to get to [my] football or basketball game." Familylike support from his coworkers was key:

... it's nice here because if you're on afternoons and you have a kid, a lot of guys will let you sneak out. Not that it's right, but they'll let you sneak out to go 
see your son play a football game or whatever, and sneak back in. They'll cover you in that respect. So that's kind of nice. That's part of the family aspect here. A couple of guys have said that. They've been stuck on afternoons and their son was at a football game. They were determined to go see it, so they worked it out with the buddies. "I'm just going to be gone for

As group members

work together to

manage the

challenge of

balancing work,

family, and personal

needs, a community

emerges where

members share a

sense of belonging,

feel that they matter

to one another, and

believe that their

needs will be met

through their

commitment to work

together. an hour, just so I can go see him and wave to him and let him know I'm there." And then they come back.

Such use of coworkers as an informal support network for managing the tensions of work and family can serve as a protective buffer from negative consequences (Blair-Loy \& Wharton, 2002). In addition, the workgroup norms that embrace family-friendly values prevent negative stigmatization of coworkers whose personal lives interfere with their work (Lambert \& Hopkins, 1995). As group members work together to manage the challenge of balancing work, family, and personal needs, a community emerges where members share a sense of belonging, feel that they matter to one another, and believe that their needs will be met through their commitment to work together (McMillian \& Chavis, 1986). This results in an ideology that helps the group cope by redefining work practices so supporting and covering for each other become the norm (Lamphere, 1985).

\section{Taking Independent Action}

Several workers took independent action to achieve personal family goals in the face of workplace constraints. James Anderson's account of pretending that he had an auto accident that kept him from returning to work after his lunch break was one example. Al- though this approach helped Anderson accomplish his immediate objective, it resulted in a lose-lose situation for him and his company: he was reassigned to a much less desirable job and the company (and his supervisor) had to struggle to meet production targets.

Other employees, in interviews or discussions in the course of the field research, provided examples of techniques they have used when confronting what they perceive to be as an otherwise insoluble conflict between work requirements and family responsibilities. These highlight how a dissatisfied worker can disrupt work. Such acts of volition represent another aspect of a supervisor's willingness to support informal flexibility-it reflects the reality that supervisors are dependent upon the cooperation of the workers they supervise for successful outcomes in their departments, and that workers can express their will through a variety of means.

At Sylvania, as in other work environments, meeting production goals, in terms of both quantity and quality, is essential. Disgruntled workers can mean missed targets. One worker demonstrated how he could vary the speed of his machine to get ahead of production targets or fall behind. He described how he had once single-handedly disrupted the production of a key Sylvania product by slowing down his machine operations in protest to a new plant rule restricting overtime. Within a day, the rule was rescinded. Another worker admitted that he had been given permission to take time off to travel to his son's Bible quiz tournaments because his supervisor knew that if he did not allow him the time off or docked his pay, the employee had ways to retaliate:

So I consider-hurry up and fixing this and getting back on line and runnin' your production will make you look like a hero? I kept the son of a bitch down. And I mix [the machine settings] up a little bit to where the guy came in on the next shift couldn't put it back together and be sittin' there waiting for me to put it back together [laughs]. . . . You gotta know your machine-machinery-well enough to be able to do it that way. 
You're really not sabotaging the machine ... It's just that "Oh, I guess I should have put it back that way."

This incident illustrates how a worker can take disruptive actions as a response to the conflict between the demands of a rigid work environment and family responsibilities. As suggested in the interview, threatening to retaliate by disrupting production gave this employee feelings of control (Analoui, 1995). Employees who successfully sabotage a production process can nullify a negative work experience by making themselves feel courageous and competent (Giacalone \& Rosenfeld, 1987).

\section{Extending the Findings}

In addition to sports, the time conflicts and coping mechanisms discussed reflect the challenges posed by other family activities whose rhythms and schedules clash with in- flexible work schedules. To address these issues, organizations can implement several policies and practices. In this context, our study makes several contributions to the human resource management literature addressing work-family conflict. Also, based on our findings, in this section we present recommendations for practitioners. These recommendations are summarized in Table II.

\section{Implications for Research}

In this study, the manufacturing context presents an alternative setting for work-family research, which has often focused on corporate office settings and knowledge-intensive work. In white-collar settings, long hours may be problematic, but work schedules are often fluid, flextime is common, and traditional shift work is usually not an issue when balancing work and family commitments. The rigidities seen at Sylvania provide a window for examining more structured

\section{T A B L E I I Recommendations for Managing Work-Family Conflict of Fathers and Shift Workers}

\section{Challenge}

Work-family conflict as a result of inflexible shift work

Workplace exclusion of fathers from family-friendly policies and practices

Leveraging informal approaches to balance work and family

\section{Recommendation}

- Provide human resource management coverage and services for extended hours operations.

- Human resource managers become a part of the extended-hours operation team to serve as a resource to help with the implementation of familyfriendly policies.

- Redefine flexible work arrangements to take into account the needs of shift workers.

- Support the provision of child care beyond traditional work hours.

- Offer training to employees that identifies strategies for managing the tensions of shift work and family responsibilities.

- Conduct a systematic analysis of the needs of working fathers so that organizational policies can help them manage work-family conflict.

- Foster a work culture where it is an acceptable norm for fathers to take advantage of family-friendly policies.

- Create affinity groups for working fathers where they can share ideas and support each other.

- Align formal family-friendly policies with informal support mechanisms.

- Train supervisors and middle-managers to support those dealing with work-family conflicts.

- Build an organizational culture that values flexibility, high-quality peer relationships, and trust as the cornerstones of a family-friendly work environment. 
work environments, and this allows us to include temporal diversity when exploring the balance between work and family life. Shift work and the lack of flexibility at Sylvania also are characteristic of many service-sector workplaces, such as retail, hospitality, and health care. The Sylvania interviews reveal the problems faced by parents in a broad range of jobs. Parents who work nontraditional hours can become socially marginalized and out of sync with their children's activities, which are Managers must typically organized around the decide how to focus traditional work schedule (Presser, 2003; Wilson, Debruyne, Chen, \& Fernandes, 2007).

The project at Sylvania reinon organizational goals, such as efficiency, quality, and competitive advantage, while creating a workplace culture

built on trust, shared values, and compassion. forces the need for studies that focus on the obstacles faced by those in nontraditional work arrangements. It challenges researchers to consider whether current theories on work-life balance offer insight for those in shift jobs, rigidly coordinated work, and blue-collar jobs.

This research encourages scholars to dig deeper to understand how individuals effectively integrate multiple roles. For many of those in nontraditional work arrangements, flexible work arrangements, on-site child care, and predictable job scheduling are not viable for integrating work and family roles. What strategies do these individuals use to manage multiple roles? As the Sylvania project showed, sometimes workers devise unique coping mechanisms to help them balance work-life issues in nontraditional work arrangements. Although this research identified several coping mechanisms, we believe this is just a starting point. Future researchers may want to investigate the role of support from other family members and friends in balancing rigidly scheduled work and family obligations.

From a managerial perspective, this research calls attention to the role of leadership in helping employees integrate multiple roles. Not only did the workers at Sylvania struggle with balancing work and family life, but several supervisors also struggled with meeting organizational goals while creating a family-friendly work environment. Managers must decide how to focus on organizational goals, such as efficiency, quality, and competitive advantage, while creating a workplace culture built on trust, shared values, and compassion (Dennison, Hooijberg, \& Quinn, 1995). As we learned from Sylvania, the ineffective management of these competing goals can have negative consequences.

In addition, our experiences at Sylvania highlight the significance of organizational ethnography as a mechanism for studying human resource management. A central aspect of organizational ethnography is fieldwork, and this involves penetrating organizations to grasp a native viewpoint (Bates, 1997). Through interviews and observations of Sylvania's organizational members, we were able to explore the complexity of how fathers attempt to meet the demands of work and family in a rigid work setting. In contrast to surveys, the ethnographic interviews provided an in-depth perspective of those fathers and their challenges, revealing the cultural underpinning of their decisions. This approach built upon previous research on tensions between work and family by capturing a contextual and process perspective of individuals.

In particular, the context of the field work was important because it allowed us to establish links between individuals and their occupational setting, and to study the coping mechanisms that emerged as processes for balancing work and family. These mechanisms provided snapshots of the formal and informal aspects of family-friendly work policies, the consequences of independent versus group- or supervisor-supported actions, and the interplay of the give-and-take system that management and employees engage in to resolve work-family conflict issues.

\section{Implications for Practice}

At Sylvania, we found that fathers worried about missing not only extracurricular activities, but also important developmental 
milestones in the lives of their children. These findings provide human resource managers and researchers with a compelling rationale for exploring how organizations can create a family-friendly work environment for shift workers. Although HR policies can help create a family-friendly work environment, in many companies HR management is the missing link. In the United States, only 21 percent of extendedhours companies report providing HR management coverage for the evening, night, and weekend shifts, and HR managers usually are not represented on the extended operations teams (Circadian Technologies, Inc., 2004).

Yet, this is an opportunity for human resource executives to serve on extended operations teams and to create specific family-friendly policies for shift workers. The expertise of HR management executives is needed on these teams, especially since employees working nontraditional hours have higher levels of absenteeism, turnover, and fatigue-related injuries than workers on traditional shifts, exacerbating work-family conflicts (Circadian Technologies, Inc., 2004; Presser, 2003). HR management policies can help redefine flexible work arrangements, support the provision of child care beyond traditional work hours, and implement other programs to reduce conflicts between work and family life. There should not be a substandard set of work-family policies for shift workers or employees in a rigidly scheduled environment. Moreover, there is a need for an infrastructure that supports access to these programs.

The Sylvania interviews also emphasized the importance of including fathers in the work-family equation. Although the interviews discussed here focused on sports, they also revealed a broad range of paternal responsibilities. Current policies often focus on mothers, with only secondary considerations for fathers. However, fathers engage in complementary and alternative parenting activities for which work schedules can create serious conflicts. Furthermore, the importance of fathering is increasing as more women enter the workforce and societal values change. This has created a new generation of working fathers who are taking on a broader spectrum of parenting responsibilities. The narratives from this research, illustrating involvement with children's sports activities, are but only one example of parenting responsibilities of working families. The parent-sport analysis highlights the broader question of how workplace policies and practices can help fathers balance work and family.

How can corporate work-life balance programs become viewed as less of a "mommy thing" and be designed to address the needs of fathers as well? HR managers may have to reconceptualize the design of their family-friendly work programs to be more inclusive of fathers. Although many organizations have formal paternity leave and flexible work options, this is only a starting point (Reeves, 2002). In addition to offering paternity leave, organizations should conduct a systematic analysis of the needs of their working fathers and create an organizational culture in which it is acceptable for fathers to take advantage of family-friendly policies and to speak up about their work-family balance needs without being penalized or con-
The Sylvania

interviews also

emphasized the

importance of

including fathers in

the work-family

equation. Although

the interviews

discussed here

focused on sports,

they also revealed a

broad range of

paternal

responsibilities. sidered uncommitted (Mass, 2004). In other words, barriers have to be removed so that the workplace accepts the role of both fathers and mothers in parenting instead of viewing fathers solely as breadwinners (Haas \& Hwang, 1995).

This research reemphasizes the significance of organizational culture, informal policies, and work relationships in reducing work-family conflict. The employees at Sylvania used their supervisors and coworkers as key resources to help balance work and family life. The ability to rely on supervisors and coworkers is a reflection of the organizational culture in a workplace. Our find- 
ings are consistent with other research on the importance of positive organizational cultures and support for work-family initiatives among middle management and supervisory personnel (Bond, Galinsky, \& Swanberg, 1998; Friedman \& Johnson, 1997). Relationships with supervisors and coworkers explain a large part of the variance in the work-family balance. We see how the organizational culture-"this is a family plant" - plays a key role in how parents navigate their rigid work schedules to be involved in their children's extracurricular activities.

In the absence of a supportive work culture or supervisors, some employees may take independent action or even engage in workplace sabotage. This suggests that there is a need for organizational structures, trained management, and HR policies that can address these issues before the strain of work-family conflict becomes problematic, unproductive, and costly (Analouoi, 1995; Hill, 2003). The prevention of un- and counterproductive independent actions may call for a paradigm shift on how organizations address work-family conflict. Although organizational leaders are aware of this need, in many instances they ignore it or take a reactive approach by addressing a problem only after it becomes a crisis and manifests itself in employee sabotage, high turnover, or the inability to attract new employees. Instead, leaders should be proactive and craft formal work-family policies that complement informal approaches. This would result from a systematic approach where management works to build a bridge between formal, written family-friendly policies and the organization's culture, high-quality peer relationships, trust, and the support of supervisors.

Finally, both researchers and practitioners must consider the organizational implications of rigid work schedules. That is, to what extent do organizations with rigid work schedules experience more absenteeism and lower employee productivity because of work-family conflict? Is there a link between rigid work schedules/conflicting family activities and employee satisfaction? If so, how can organizations develop policies that permit employees to fulfill work and family responsibilities while maintaining rigid work schedules?

Addressing these issues presents an important set of challenges for HR managers and for employers in general. As the constellation of family structures, parental roles, and work schedules shifts, organizational leaders must recognize and adapt to these conditions to reconcile the demands of work and family and ensure the stability and success of both.

\section{Acknowledgment}

The research for this article was generously supported by the Alfred P. Sloan Foundation and its University of Michigan Center for the Ethnography of Everyday Life. During the study, seven individuals served on the research team at different periods: Bob Bowen, Dilli Dehal, Tom Fricke, Pete Richardson, Lawrence Root, Elizabeth Rudd, and Alford Young, Jr. Elizabeth Rudd and Lawrence Root carried out most of the semistructured interviews.

LAWRENCE S. ROOT is a professor in the University of Michigan's School of Social Work and director of the Institute of Labor and Industrial Relations. His research focuses on the intersection of employment and social welfare, including employee benefits and social insurance, personnel practices for an aging workforce, services for workers experiencing personal problems, joint labor-management programs, and work-family issues. Professor Root has directed research-service projects focusing on employee assistance programs, education and training, and distance learning in the auto industry. He also has worked on issues of international labor standards and chairs the University of Michigan's Committee on Labor Standards and Human Rights. 
LYNN PERRY WOOTEN is a clinical assistant professor of strategy, management, and organizations at the University of Michigan Ross School of Business. Prior to joining the faculty at the Ross School of Business, she was an assistant professor at the University of Florida. Professor Wooten's research projects focus on sources of competitive advantages in organizations and how firms strategically adapt to changes in their labor markets. In addition, she studies crisis leadership, positive organizing routines, and the effectiveness of diversity programs in organizations. Her research has been published in academic journals, such as the Academy of Management Journal, American Behavioral Scientist, the Journal of Management Inquiry, and Sex Roles. Also her research has been featured in newspapers, industry trade journals, and radio shows. She consults in the areas of strategic human resource management, organizational development, and workforce diversity with both profit and not-for-profit organizations.

\section{NOTE}

1. Pseudonyms are used throughout this article for the individuals quoted and the factory where they work. Some descriptions have been altered to further protect the identity of the individuals who were studied. No changes were made that would affect the content being reported.

\section{REFERENCES}

Almeida, D., \& McDonald, D. (2005). The time Americans spend working for pay, caring for families, and contributing to communities. In J. Heymann (Ed.), Unfinished work: Balancing equality and democracy in an era of working families (pp. 180-203). New York: The New Press.

Analoui, F. (1995). Workplace sabotage: Its styles, motives, and management. Journal of Management, $14(7), 48-65$.

Anderson, S., Coffey, B., \& Byerly, R. (2002). Formal organizational initiatives and informal workplace practices: Links to work-family conflict and job-related outcomes. Journal of Management, 28, 787-810.

Barnett, R. C., \& Marshall, N. L. (1992). Worker and mother roles, spillover effects, and psychological distress. Women \& Health, 18(2), 9-40.

Bates, S. P. (1997). Whatever happened to organizational anthropology? A review of the field of organizational ethnography and anthropological studies. Human Relations, 50, 1147-1175.

Beers, T. M. (2000). Flexible schedules and shift work: Replacing the "9 to 5" workday? Monthly Labor Review, 123(6), 33-40.
Bell, E. L., \& Nkomo, S. M. (1992). Re-visioning women manager's lives. In A. J. Mills \& P. Tancred (Eds.), Gendering organizational analysis (pp. 235-247). Newbury Park, CA: Sage.

Billings, A. G., \& Moos, R. H. (1982). Work stress and the stress-buffering roles of work and family resources. Journal of Occupational Behavior, 3, 215-232.

Blair-Loy, M., \& Wharton, A. (2002). Employees' use of work-family policies and the workplace social context. Social Forces, 80, 813-845.

Bond, J. T., Galinsky, E., \& Swanberg, J. E. (1998). The 1997 national study of the changing workforce. New York: Families and Work Institute.

Bonney, J., Kelley, M., \& Levant, R. (1999). A model of fathers' behavioral involvement in child care in dual-earner families. Journal of Family Psychology, 13, 401-415.

Bowen, G. L. (1988). Corporate support for the family lives of employees. A conceptual model for programming and planning. Family Relations, 37(2), 183-188.

Bruce, W., \& Reed, C. (1994). Preparing supervisors for the future work force:The dual-income couple and the work-family dichotomy. Public Administration Review, 54(1), 36-43.

Circadian Technologies, Inc. (2004). Working Nights. Retrieved February 12, 2008, from http://www.circadian.com

Clark, S. (2000). Work/family border theory: A new theory of work/family balance. Human Relations, 53, 747-770.

Collins, B., McDonald, T., \& Mousa, J. A. (2007). The rise and decline of auto parts manufacturing in the Midwest. Monthly Labor Review, 130(10), 14-20. 
Connell, R. (1995). Masculinities. Berkley, CA: University of California Press.

Costa, G. (1996). Effects on health and well-being. In W. P. Colauhoun, G. Costa, S. Folkard, and P. Kanuth (Eds.), Shiftwork: Problems and solutions (pp. 113-139). Frankfurt/Main: Peter Lan.

Dallimore, E. J., \& Mickel, A. E. (2006). Quality of life: Obstacles, advice, and employer assistance. Human Relations, 59(1), 61-103.

Demerouti, E., Geurst, S., Bakker, S., \& Euwema, M. (2004). The impact of shiftwork on work-Home conflict, job attitudes and health. Ergonomics, 47, 987-1002.

Dennison, D., Hooijberg, R., \& Quinn, R. (1995). Paradox and performance: Toward a theory of behavioral complexity in managerial leadership. Organization Science, 6, 522-540.

Eby, L. T., Casper L. T., Lockwood, W. J., Bordeaux, A. C., \& Brinley, A. (2005). Work and family research in IO/OB: Content analysis and review of the literature (1980-2002). Journal of Vocational Behavior, 66, 124-197.

Friedman, D. E., \& Johnson, A.A. (1997). Moving from programs to culture change: The next stage for the corporate work-family agenda. In S. Parasuraman \& J. H. Greenhaus (Eds.), Integrating work and family: Challenges and choices for a changing world (pp. 209-219). Westport, CT: Quorum Books.

Frone, M., Russell, M., \& Cooper, M. L. (1992). Antecedents and outcomes of work-family conflict: Testing a model of the work-family interface. Journal of Applied Psychology, 77(1), 65-78.

Frone, M., \&Yardley, J. (1996). Workplace family-supportive programs: Predictors of employed parents' importance rating. Journal of Occupational and Organizational Psychology, 69, 351-366.

Gavanas, A. (2004). Fatherhood politics in the United States: Masculinity, sexuality, race, and marriage. Urbana, IL: University of Illinois Press.

Gephart, R. (1993). The textual approach: Risk and blame in disaster sense-making. Academy of Management Journal, 36, 1465-1514.

Giacalone, R., \& Rosenfeld, P. (1987). Reasons for employee sabotage in the workplace. Journal of Business \& Psychology, 1, 367-377.

Greenhaus, J., \& Beutell, N. (1985). Sources of conflict between work and family roles. Academy of Management Review, 10(1), 76-88.

Griswold, R. (1993). Fatherhood in America. New York: Basic Books.

Haas, L., \& Hwang, P. (1995). Company culture and men's usage of family leave benefits in Sweden. Family Relations, 44(1), 28-36.

Haddock, S. A., Zimmerman, T. S., Lyness, K. R., \& Ziemba, S. (2006). The workplace strategies of successful dual-earner couples. Journal of Economic Issues, 27(2), 207-234.

Hill, E. J. (2003). Studying "working fathers": Comparing fathers' and mothers' work-family conflict, fit, and adaptive strategies in a global high-tech company. Fathering: A Journal of Theory, Research and Practice, 1, 239-261.

Hill, E. J. (2005). Work-family facilitation and conflict, working fathers and mothers, work-family stresses and support. Journal of Family Issues, 26, 793-819.

Hochschild, A. (1997). The time bind: When work becomes home and home becomes work. New York: Metropolitan Books.

Ingrassia, P., \& White, J. B. (1994). Comeback: The fall and rise of the American automobile industry. New York: Simon and Schuster.

Kerry, D., \& Palkovitz, R. (2004). Reworking work and family issues for fathers. Fathering: A Journal of Theory, Research, and Practice about Men as Fathers, 2(3), 211-213.

Lambert, S., \& Hopkins, K. (1995). Occupational conditions and workers' sense of community: variations by gender and race. American Journal of Community Psychology, 23(2), 151-179.

Lamphere, L. (1985). Bringing the family to work: Women's culture on the shop floor. Feminist Studies, 11, 519-540.

Levine, J., \& Pittinsky, T. (1997). Working fathers: New strategies for balancing work and family. Reading, MA: Addison-Wesley.

Mass, A. (2004). Father-friendly benefits can improve a company's bottom line. Employee Benefit News. Retrieved May 20, 2008, from http://findarticles.com/p/articles/mi_km2922/is_/ai_n 8622556

Maynard, M. (2003). The end of Detroit: How the Big Three lost their grip on the American car market. New York: Doubleday.

McMillian, D., \& Chavis, D. (1986). Sense of community: A definition and theory. Journal of Community Psychology, 14, 5-23.

Messner, M. (1992). Power at play: Sports and the production of masculinity. Boston, MA: Beacon Press.

Miles, M. B., \& Huberman, A. M. (1994). Qualitative data analysis. (2nd ed.). Thousand Oaks, CA: Sage.

Muller, H., \& Rowell, M. (1997). Mexican women man- 
agers: An emerging profile. Human Resource Management, 36, 429-435.

Netemeyer, R. G., Boles, J. S., \& McMurrian, R. (1996). Development and validation of work-family conflict and family-work conflict scales. Journal of Applied Psychology, 81, 400-410.

Ollerenshaw, J., \& Creswell, J. (2002). Narrative research: A comparison of two restorying data analysis approaches. Qualitative Inquiry, 8, 329-347.

Ouchi, W. (1980). Markets, bureaucracy and clans. Administrative Science Quarterly, 25, 129-141.

Parasuraman, S., \& Greenhaus, J. H. (1997). The changing world of work and family. In S. Parasuraman \& J. H. Greenhaus (Eds.), Integrating work and family: Challenges and choices for a changing world (pp. 3-13). Westport, CT: Quorum Press.

Pleck, J. H. (1997). Paternal involvement: Levels, sources, and consequences. In M. E. Lamb (Ed.), The role of the father in child development (3rd ed., pp. 66-103). New York: Wiley.

Powell, G. N., \& Mainiero, L. A. (1999). Managerial decision making regarding alternative work arrangements. Journal of Occupational and Organizational Psychology, 72(1), 41-56.

Presser, H. (2003). Working in a 24/7 economy: Challenges for American families. New York: Russell Sage Foundation.

Reeves, R. (2002). Dad's army: The case for fatherfriendly workplaces. London: The Work Foundation.

Root, L. S. (2006). Introduction to Sylvania: Changing economics of the auto industry and implications for work and family (Working Paper). Ann Arbor, MI: University of Michigan, Sloan Center for the Ethnography of Everyday Life.

Scandura, T. A., \& Lankau, M. J. (1997). Relationships of gender, family responsibilities and flexible work hours to organizational commitment and job satisfaction. Journal of Organizational Behavior, 18, 377-391.

Schor, J. (1991). The overworked American: The un- expected decline in leisure. New York: Basic Books.

Secret, M., \& Sprang, G. (2001). The effects of family friendly workplace environments on work-family stress of employed parents. Journal of Social Service Research, 28(2), 21-45.

Staines, G. L., \& Pleck, J. H. (1984). Nonstandard work schedules and family life. Journal of Applied Psychology, 69, 515-523.

Staines, G. L., \& Pleck, J. H. (1986). Work schedule flexibility and family life. Journal of Occupational Behavior, 7, 147-153.

Strauss, A., \& Corbin, J. (1998). Basics of qualitative research: Techniques and procedures for developing grounded theory (2nd ed.). Thousand Oaks, CA: Sage.

Tretheway, A., \& Ashcraft, K.L. (2004). Practicing disorganization: The development of applied perspectives on living with tension (Introduction to the special issue). Journal of Applied Communication Research, 32(2), 81-88.

Van Manen, M. (1990). Researching lived experience: Human science for an action sensitive pedagogy. Albany, NY: SUNY Press.

Warren, J., \& Johnson, P. (1995). The impact of workplace support on work-family role strain. Family Relations, 44, 163-169.

Wilson, M., Debruyne, A., Chen, S., \& Fernandes, S. (2007). Shift work interventions for reduced workfamily conflict. Employee Relations, 29(2), 162-177.

Womack, J. P., Jones, D. T., \& Roos, D. (1990). The machine that changed the world. New York: Rawson Associates.

Wooten, L., \& Finley, J. (2003). Transforming business environments: Strategic investments in family-oriented cultures does matter. Business Research Yearbook: Global Perspectives, 10, 442-447.

Yeung, W., Sandberg, J., Davis-Kean P., \& Hofferth, S. (2001). Children's time-use with fathers in intact families. Journal of Marriage and the Family, 63(1), 136-154. 